\author{
Leona M. Schmidt-Speicher*, Tobias Mellert, Andrea C. Hurtado Rivera, \\ Dr. Kerstin Länge, Dr. Ralf Ahrens, Prof. Dr. Andreas E. Guber
}

\title{
Rapid Prototyping of Moulds for PDMS-based Microfluidic Chips
}

\begin{abstract}
To shorten the production time for PDMS-moulds by additive manufacturing (AM) several 3D printers have been investigated in comparison to standard micro-milling by producing benchmark structures. These are evaluated regarding their shape accuracy, the transparency of the casted PDMS which is linked to the surface quality of the mould, and the production time until the moulds are ready to use. Even though the additively manufactured moulds showed significantly better surface quality and shorter production time, the necessary shape accuracy for non-square-structures or structures with $<250 \mu \mathrm{m}$ edge length could not be achieved due to limiting factors like nozzle diameter, size of the digital micromirror device or spot size of the LCD-panel.
\end{abstract}

Keywords: Rapid Prototyping, Additive Manufacturing, Microfluidic Systems, Lab-on-a-Chip, Plant-on-a-Chip

https://doi.org/10.1515/cdbme-2021-2065

\section{Introduction}

Making microfluidic chip prototypes using polydimethylsiloxane (PDMS) to cast (used in this article as "poured and cured") the target microstructure is a standard procedure in microfluidic research. But, manufacturing the according moulds (used in this article as "the cavity to shape the casted material) by micro-milling from polymers like polymethylmethacrylate (PMMA) is a time-consuming process. Furthermore, certain structures cannot be milled directly, and the surface quality of fast micro-milled polymer parts is not

\footnotetext{
*Corresponding author: Leona M. Schmidt-Speicher: Karlsruhe Institute of Technology (KIT), Institute of Microstructure Technology (IMT), Hermann-von-Helmholtz-Platz 1, 76344 Eggenstein-Leopoldshafen, Germany, e-mail: leona.schmidtspeicher@kit.edu,

Tobias Mellert, Andrea C. Hurtado Rivera, Dr. Kerstin Länge, Dr. Ralf Ahrens, Prof. Dr. Andreas E. Guber: KIT, IMT, 76344 Eggenstein-Leopoldshafen, Germany
}

sufficient for adequate moulding of PDMS, making slow infeed and special cutting tools necessary. Metal as mould material as well as the use of special diamond-milling-tools can improve the surface quality but increase the manufacturing costs significantly at the same time.

Since the late $2000 \mathrm{~s}$, the precision and size of parts that can be manufactured by AM has improved considerably. The usually much shorter manufacturing time was always an interesting factor for possible applications in research as it allows quicker evaluation of designs, production costs are often lower compared to a milled part, and many processes allow the direct manufacturing of geometries that cannot be milled directly. [ $1-5]$ Therefore, various 3D printers have been investigated regarding their suitability for rapid mould production for PDMS casts.

\section{Materials and Methods}

The tests were conducted on identical mould structures of a microfluidic root chip design (see Figure 1). These Plant-ona-Chip-systems can be used to study root growth in a laboratory environment.

\subsection{Applied manufacturing methods}

The identical mould structures were manufactured by AM using fused filament fabrication (FFF), and stereolithography (SL), and by micro-milling as a reference.

The tested printers were an Ultimaker 3 (Ultimaker, Netherlands) and Prusa i3 Mk3S (Prusa, Czech Republic) as examples of an FFF process and a Prusa SL, MiiCraft+ (MiiCraft, Taiwan) and Creality LD-002H (Creality, China) to represent the SL-manufacturing. The selected printers represent a selection of widely available printers of the most common AM principles (FFF \& SL). For the FFF-printers, the limiting factor regarding precision is the filament nozzle. Its diameter is strongly related to the minimal amount of filament that can be deposited. For the SL-printers MiiCraft + and Prusa SL1, the digital micromirror device (DMD) limits 

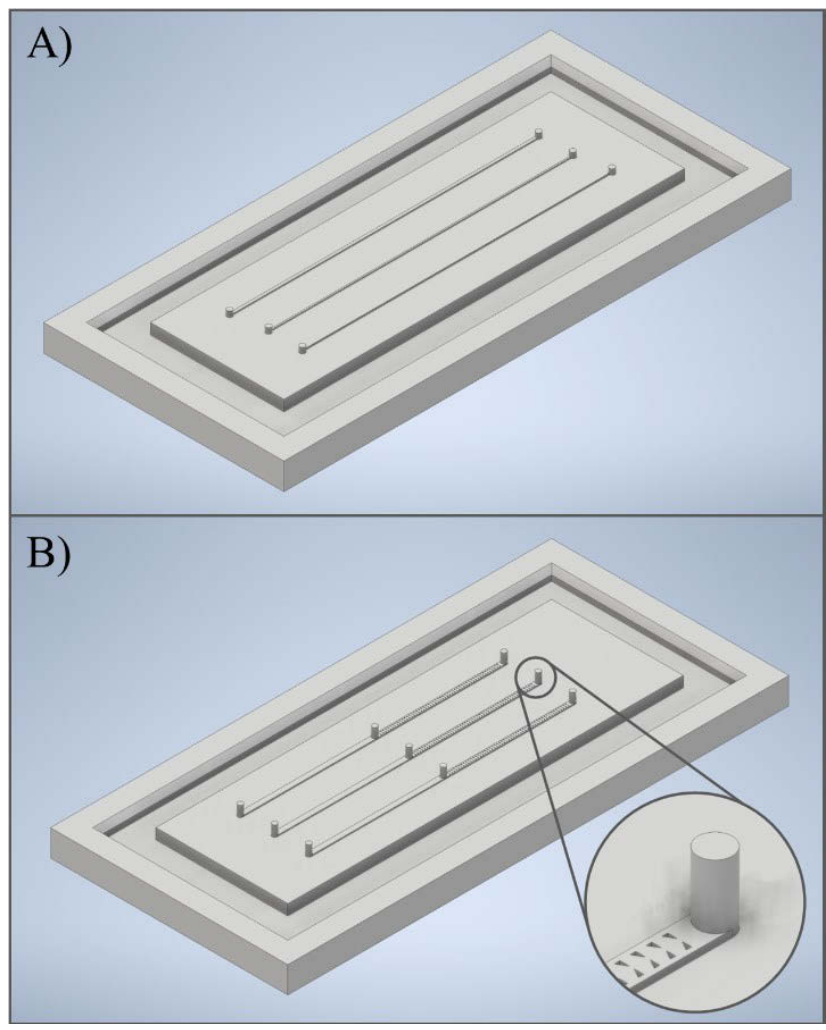

Figure 1: Benchmark mould structures: A) Standard channels (widths: $100 \mu \mathrm{m}, 250 \mu \mathrm{m}$, and $500 \mu \mathrm{m}$ ). B) Mould with directional structures. Triangular structures: $150 \mu \mathrm{m} \times 260 \mu \mathrm{m} \times 300 \mu \mathrm{m}$, centre-distance: $150 \mu \mathrm{m}$, channel width: $970 \mu \mathrm{m}$.

the minimally irradiated spot size which is generally indicated in ppi (pixel per inch). For the Creality $L D-002 H$ the precision is determined by the resolution of the Monochrome LCD Display.

The micro-milled moulds were manufactured on a Deckel FP3 NC (Friedrich Deckel AG, Germany) mill from PMMA. This process was limited by the diameter of the milling-tool (standard structure: $2 \mathrm{~mm}$, triangular directional structures: $0.1 \mathrm{~mm}$ ) and the maximal possible infeed in $\mathrm{z}$ direction (standard structure: $40 \mu \mathrm{m}$, triangular directional structures: $5 \mu \mathrm{m}$ ) of it.

While the standard structure could be milled directly, the cavities for the directional structures could not be manufactured due to their triangular shape. Instead, the final - positive - structure was milled in PMMA and then casted in PDMS which was then processed to serve as the final mould. For this process, the surface of the first cast was activated in an oxygen-plasma for $30 \mathrm{~s}$ at $0.016 \mathrm{slm}$ oxygenflow in a 4Tec-Plasma-Etcher. Next, this first cast was transferred to a desiccator, evacuated to 650 mbar below atmosphere for $2 \mathrm{~h}$ together with $20 \mu \mathrm{l}$ of a solution of trichloro $(1 \mathrm{H}, 1 \mathrm{H}, 2 \mathrm{H}, 2 \mathrm{H}$-perfluorooctyl)silane

(PFOTS,
$0.3 \mathrm{vol} \%$ ) in cyclohexane. This prevented the adhesion of the PDMS mould to the subsequently casted PDMS, and the so created mould could be used several times.

\subsection{Used materials and postprocessing}

The achieved results strongly depend on the combination of used material and manufacturing device. For the Ultimaker 3 FFF prints, Acrylonitrile-Butadiene-Styrene (ABS) was used, and for the Prusa i3 Mk3S test, the material was Polylactide (PLA). PLA was used, because there was no other filament material available for the tests on this printer.

The moulds generated through SL used three different photopolymer-sresins: For the MiiCraft + it was NOVA3D LCD UV Resin 405nm Rapid Resin Black (RRB), for the Prusa SL 1 RRB and NOVA3D LCD UV Resin 405nm Rapid Resin Cyan (RRC), and for the Creality $L D-002 H$ Elegoo Standard LCD UV-Curing Photopolymer Rapid Resin (ESR). Some moulds needed additional postprocessing (table 1) to make the material suitable for casting PDMS.

Table 1: Material and parameter overview of applied processes and postprocessing of surfaces

\begin{tabular}{|c|c|c|c|c|}
\hline $\begin{array}{l}\text { Printer/ } \\
\text { Milling } \\
\text { Machine }\end{array}$ & $\begin{array}{l}\text { Limiting } \\
\text { Factor (min. } \\
\text { value) }\end{array}$ & Material & $\begin{array}{l}\text { Layer } \\
\text { thickness/ } \\
\text { Stepdown }\end{array}$ & $\begin{array}{l}\text { Post } \\
\text { Processing } \\
\text { of Mould }\end{array}$ \\
\hline Ultimaker 3 & $\begin{array}{l}\text { Nozzle } \\
(\varnothing 250 \mu \mathrm{m})\end{array}$ & ABS & $60 \mu \mathrm{m}$ & None \\
\hline $\begin{array}{l}\text { Prusa i3 } \\
\text { Mk3S }\end{array}$ & $\begin{array}{l}\text { Nozzle } \\
(\varnothing 250 \mu \mathrm{m})\end{array}$ & PLA & $250 \mu \mathrm{m}$ & None \\
\hline MiiCraft+ & $\begin{array}{l}\text { DMD (450 ppi } \\
\hat{=} 56 \mu \mathrm{m})\end{array}$ & RRB & $25 \mu \mathrm{m}$ & $\begin{array}{l}>14 \mathrm{~h} \text {, oven } \\
\text { at } 85^{\circ} \mathrm{C}\end{array}$ \\
\hline Prusa SL1 & $\begin{array}{l}\text { DMD (540 ppi } \\
\triangleq 47 \mu \mathrm{m})\end{array}$ & $\begin{array}{l}\text { RRB \& } \\
\text { RRC }\end{array}$ & $25 \mu \mathrm{m}$ & $\begin{array}{l}>14 \mathrm{~h} \text {, oven } \\
\text { at } 85^{\circ} \mathrm{C}\end{array}$ \\
\hline $\begin{array}{l}\text { Creality LD- } \\
002 H\end{array}$ & $\begin{array}{l}\text { LCD-display } \\
\text { (504 ppi } \\
\hat{=} 51 \mu \mathrm{m})\end{array}$ & ESR & $50 \mu \mathrm{m}$ & $\begin{array}{l}>12 \mathrm{~h}, \\
\text { sunlight }\end{array}$ \\
\hline $\begin{array}{l}\text { Deckel FP3 } \\
\text { NC }\end{array}$ & $\begin{array}{l}\text { Tool- } \varnothing \\
\text { (smallest } \\
\text { used tool: } \\
0.1 \mathrm{~mm} \text { ) }\end{array}$ & PMMA & $\begin{array}{l}\text { Standard: } \\
40 \mu \mathrm{m} \text {, } \\
\text { directional: } \\
5 \mu \mathrm{m}\end{array}$ & $\begin{array}{l}\text { PFOTS- } \\
\text { coating of } \\
\text { PDMS cast of } \\
\text { the positive } \\
\text { PMMA- } \\
\text { structure }\end{array}$ \\
\hline
\end{tabular}

\subsection{Analysis of moulds}

The generated moulds and PDMS casts were qualitatively analysed using an Axioscope 7 microscope (Zeiss, Germany) 
equipped with an Axioscope 205 Color camera regarding the shape accuracy of the mould and other striking features or defects. Furthermore, it was tested if the PDMS could be removed from the mould without leaving residues. Then, the casted PDMS was evaluated by sight on its transparency which is a first indicator on the surface quality of the mould.

The surface roughness parameters $\mathrm{Ra}, \mathrm{Rq}$, and $\mathrm{Wa}$ of the generated moulds were analysed via vertical scanning interferometry (VSI) with a Contour GT-K VSI (Bruker Corporation, USA) at five different spots in different orientations on the mould surface. According to their definition in DIN EN ISO 4287 Ra relates to the averaged roughness amplitude of a surface and $\mathrm{Rq}$ is the defined as the root mean square of $\mathrm{Ra}$, but these values do not state any other information on the shape of the profile. Wa quantifies the waviness of a surface, which describes the surface shape in longer periods. Furthermore, the standard channel structure profiles were measured with the VSI to quantitatively evaluate the shape accuracy of the various processes.

Finally, the moulds were qualitatively evaluated using the scanning electron microscope Zeiss EVO 10 to get pictures with more depth of field.

\section{Results}

The resulting moulds were evaluated regarding their mouldability and production time. The casted PDMSmicrostructures were assessed according to their shape accuracy and transparency.

\subsection{Shape accuracy}

The achieved shape accuracy was evaluated with the CADmodels as reference. Regarding it, e.g., the upper and lower width of the block were assessed that would later serve as a blocker for the root growth channel. Furthermore, the heights of the generated blocks were evaluated. To be able to evaluate the different structures easier, the relative deviation of the generated moulds from the ideal model was calculated. The results are shown in table 2 . For some processes, the $100 \mu \mathrm{m}$-channels did not provide a noteworthy result. The according result lines are marked as "not manufactured".

\subsection{Surface roughness}

The surface quality was evaluated as described in 2.3. The micro-milled mould displays significant rougher surface finish than the additively manufactured moulds.
Table 2: Shape accuracy of the additively manufactured standard channel moulds relative to the ideal CAD-model. A positive deviation accounts for a bigger structure than aimed at, a negative for a smaller one.

\begin{tabular}{|c|c|c|c|c|}
\hline \multirow[t]{2}{*}{$\begin{array}{l}\text { Printer/Milling } \\
\text { Machine }\end{array}$} & \multirow{2}{*}{$\begin{array}{l}\text { Model Channel } \\
\text { Width } \\
{[\mu \mathrm{m}]}\end{array}$} & \multicolumn{3}{|c|}{$\begin{array}{l}\text { Relative Deviation from } \\
\text { Model Dimensions }\end{array}$} \\
\hline & & $\begin{array}{l}\text { Height } \\
\text { [\%] }\end{array}$ & $\begin{array}{l}\text { Top } \\
\text { Width } \\
\text { [\%] }\end{array}$ & $\begin{array}{l}\text { Bottom } \\
\text { Width } \\
\text { [\%] }\end{array}$ \\
\hline \multirow[t]{3}{*}{ Ultimaker 3} & 500 & -8 & -6 & 21 \\
\hline & 250 & 6 & 33 & 67 \\
\hline & 100 & 6 & 116 & 188 \\
\hline \multirow[t]{3}{*}{ Prusa i3 Mk3S } & 500 & 47 & 0 & 18 \\
\hline & 250 & 52 & 48 & 116 \\
\hline & 100 & \multicolumn{3}{|c|}{ not manufactured } \\
\hline \multirow[t]{3}{*}{ MiiCraft+ } & 500 & -40 & -11 & 31 \\
\hline & 250 & -43 & -14 & 62 \\
\hline & 100 & -45 & -33 & 83 \\
\hline \multirow[t]{3}{*}{ Prusa SL1 } & 500 & -8 & 4 & 38 \\
\hline & 250 & -10 & -17 & 51 \\
\hline & 100 & \multicolumn{3}{|c|}{ not manufactured } \\
\hline \multirow[t]{3}{*}{ Creality $L D-002 H$} & 500 & -52 & 5 & 55 \\
\hline & 250 & -50 & 37 & 110 \\
\hline & 100 & -51 & 12 & 143 \\
\hline \multirow[t]{3}{*}{ Deckel FP3 NC } & 500 & 4 & 1 & 41 \\
\hline & 250 & 7 & 6 & 75 \\
\hline & 100 & 5 & 39 & 150 \\
\hline
\end{tabular}

Table 3: Surface quality quantified through $\mathrm{Ra}, \mathrm{Rq}$, and Wa. Measurements were taken on top of the generated structures, as this area is significant for the final chip functionality. Per value, measurements $(n=5)$ in different orientations were taken, averaged and, the standard deviation was calculated.

\begin{tabular}{llll}
\hline $\begin{array}{l}\text { Printer/ } \\
\text { Milling Machine }\end{array}$ & $\begin{array}{l}\text { Ra } \\
\text { [nm] }\end{array}$ & $\begin{array}{l}\text { Rq } \\
\text { [nm] }\end{array}$ & $\begin{array}{l}\text { Wa } \\
\text { [nm] }\end{array}$ \\
\hline Ultimaker 3 & $425 \pm 32$ & $550 \pm 45$ & $1184 \pm 554$ \\
Prusa i3 Mk3S & $152 \pm 33$ & $197 \pm 41$ & $743 \pm 54$ \\
MiiCraft+ & $130 \pm 61$ & $172 \pm 78$ & $443 \pm 108$ \\
Prusa SL1 & $107 \pm 32$ & $120 \pm 27$ & $241 \pm 76$ \\
Creality LD-002H & $246 \pm 171$ & $281 \pm 230$ & $161 \pm 408$ \\
Deckel FP3 NC & $1895 \pm 394$ & $2273 \pm 686$ & $2210 \pm 708$ \\
\hline
\end{tabular}




\subsection{Mouldability and transparency}

Moulds made from ABS could be used for the PDMS casting process right away, and no residues sticking to the mould hampered the PDMS cast. However, due to the surface being rippled from the material deposition, the transparency of the cast is restricted. The mould made from PLA could not be used for the PDMS casting process, as it has a glass transition temperature of $57^{\circ} \mathrm{C}$ while the PDMS was cured at $65^{\circ} \mathrm{C}$.

The materials used for the SL-processes - RRB, RRC, and ESR - performed well in the tests. Directly after the AM process, the casted PDMS did not harden in every spot that was in contact with the moulds. But, if the (newly printed) moulds received a postprocessing in the oven or during the day through sunlight-exposure, the casts came out clean, leaving no residues, and displaying clear transparency.

The micro-milled reference mould showed good performance, too. Details transferred well into the cast, and after deforming, no residues were left.

The PFOTS-covered (silanized) PDMS also performed well as a mould. The structures were copied in detail to the final PDMS cast and the PDMS mould and cast could effortless be separated. The coating is durable and did not need to be renewed so far (15 completed casts).

\subsection{Manufacturing time}

For the evaluation of the manufacturing time (mt), all steps to achieve a final mould were timed and added. Here, only the $\mathrm{mt}$ of the mould with the triangular directional structures are given as this mould needed the longest on all machines.

This led to a $\mathrm{mt}$ of $7 \mathrm{~h}$ for the Ultimaker 3 (FFF-process) and $3 \mathrm{~h} 40$ min using the Prusa i3 Mk3S (FFF-process).

Regarding the SL printers, the Prusa SL1 needed $53 \mathrm{~min}$ to print the mould and the MiiCraft + took $1 \mathrm{~h} 35 \mathrm{~min}$, but the postprocessing took $14 \mathrm{~h}$ each. The Creality $L D-002 \mathrm{H}$ created the mould in $23 \mathrm{~min}$ and $12 \mathrm{~h}$ of postprocessing.

The milling process took $9 \mathrm{~h}$ in total for the directional structures, including the milling job at the workshop ( $4 \mathrm{~h})$, a first PDMS cast to create the negative mould $(1.5 \mathrm{~h})$ and finally coating this first cast with PFOTS $(3.5 \mathrm{~h})$.

\section{Discussion}

As shown in table 2, the additively manufactured moulds were not as accurate to the CAD-model as the micro-milled mould. Furthermore, the smaller the structures get the higher the relative deviation from the model becomes. However, the deviations are less strong in the z-direction (height) of the produced moulds than in the $x-y$-direction. The FFF-based processes showed many thin filament strings and fringes on the moulds, and structures of the SL-based processes were limited by the applied digital micromirror device (DMD). Thus, the limiting factors depend on the underlying production principle (SL or FFF). Overall, for the AM processes the MiiCraft+ shows the best shape accuracy and, all AM materials - after postprocessing - allowed residuefree PDMS casting.

The transparency of the casted PDMS-structures is linked to the surface quality of the generated moulds as this surface gets copied to the PDMS. The generated moulds can be divided into two groups: unrestricted transparency of the entire PDMS cast (moulds from the SL-processes on the Prusa SL1, MiiCraft+ and Creality $L D-002 H$ and the Deckel FP3 NC), and restricted transparency on the ground plate in between the channel structures (moulds generated by the Ultimaker 3).

Due to the low feed speed as well as the copying process, the mould bearing the directional structures took the longest when produced by the micro-milling-process. Regarding the production times, the $\mathrm{AM}$ processes were clearly superior. The SL-processes needed the least amount of printing time, most likely because an entire layer could be produced at once due to the use of mask projection. However, due to the postprocessing of the SL processes, the FFF processes were quickest to produce a usable mould.

\section{Conclusion}

There are two criteria that a mould must fulfil: the PDMS cast must be retractable residue-free, and the functionality of the final microfluidic system must be given. For the latter a sufficient shape accuracy must be reached, and the casted observation channel must be transparent. For structures $<250 \mu \mathrm{m}$, the AM processes did not fulfil the needed shape accuracy. However, especially the SL-based processes showed a much better surface quality than the mould accurately milled on the Deckel FP3 NC. Furthermore, the production time of all AM processes were significantly faster than the micro-milling process due to the required slow feed speed and mould-copying-process. To sum it up, the tested AM processes might be an option for structures $>250 \mu \mathrm{m}$ but are not suited to replace micro-milling as the manufacturing process for PDMS moulds with non-square structures smaller than $250 \mu \mathrm{m}$ until further improvements regarding their precision have been implemented. 


\section{Author Statement}

The authors state no funding involved and no conflict of interest. Informed consent has been obtained from all individuals included in this study. The conducted research is not related to either human or animals use.

\section{References}

[1] J. Horvath, R. Cameron, Mastering 3D Printing: A Guide to Modeling, Printing, and Prototyping, $2^{\text {nd }}$ ed. 2020., Apress, 2020, ISBN: 978-1-4842-5842-2.
[2] F. Li, N. P. Macdonald, R. M. Guijt und M. C. Breadmore, Increasing the functionalities of 3D printed microchemical devices by single material, multimaterial, and print-pauseprint 3D printing, Lab on a Chip 19, vol. 1, p. 35-49, 2019.

[3] G. Weisgrab, A. Ovsianikov und P. F. Costa, Functional 3D Printing for Microfluidic Chips, Advanced Materials Technologies, vol. 4, art. no. 1900275, 2019.

[4] A. K. Au, W. Huynh, L. F. Horowitz und A. Folch, 3D-Printed Microfluidics, Angewandte Chemie Internationale Edition, vol. 55, p. 3862-3881, 2016.

[5] A. Waldbaur, H. Rapp, K. Länge und B. E. Rapp, Let there be chip-towards rapid prototyping of microfluidic devices: one-step manufacturing processes, Analytical Methods, vol. 3, p. 2681-2716, 2011. 